\title{
Morph-Anatomical Studies and Antibacterial Activities of the Rhizome of Zingiber officinale Roscoe
}

\section{Ahlam Salih Eltahir ${ }^{*}$, Massara Ibrahem Elnoor ${ }^{1}$, Sarrah Menahi1, Eiman Mohammed Ali Mustafa ${ }^{2}$}

${ }^{1}$ Department of Botany, Faculty of Science and Technology, Omdurman Islamic University, Khartoum, Sudan ${ }^{2}$ Department of Biology, The University College in Al-Khafji, Hafr El-Batin University, Al-Khafji, Saudi Arabia Email: *ahlam.eltahir@yahoo.com

How to cite this paper: Eltahir, A.S., Elnoor, M.I., Menahi, S. and Mustafa, E.M.A. (2018) Morph-Anatomical Studies and Antibacterial Activities of the Rhizome of Zingiber officinale Roscoe. Open Access Library Journal, 5: e4890.

https://doi.org/10.4236/oalib.1104890

Received: September 7, 2018

Accepted: October 12, 2018

Published: October 15, 2018

Copyright $\odot 2018$ by authors and Open Access Library Inc.

This work is licensed under the Creative Commons Attribution International License (CC BY 4.0).

http://creativecommons.org/licenses/by/4.0/

\begin{abstract}
In this study, morphanatomical study and antibacterial activity of the rhizome of Zingiber officinale (Zingiberaceae) were investigated to assist as a relevant source of information and contribute towards the standards to dispose the quality and identity of this plant to avoid adulterations. The transverse section of the rhizome includes different types of tissues which are epidermis, cork, cortex and vascular bundles. The cortex is formed of parenchyma cells, which often contain starch and oils in large amounts. In vitro antibacterial activity was investigated by cork porous method. The most sensitive bacteria for all concentrations of the methanolic and only $50 \mathrm{mg} / \mathrm{ml}$ for the water extract was Staphylococcus aureus. Pseudomonas aeruginosa was found to be sensitive for both extracts used. Bacillus subtilis was sensitive for the methanolic extract only. Escherichia coli was found to be not sensitive except for $100 \mathrm{mg} / \mathrm{ml}$ concentration of the methanolic extract.
\end{abstract}

\section{Subject Areas}

Plant Science

Keywords

Zingiber officinale, Zingiberaceae, Morphanatomy, Antibacterial

\section{Introduction}

Medicinal plants are used as primary health care aid among $80 \%$ of the world's 
population in the form of plant extracts or their active components [1]. Today there is a renewed interest in drugs of natural origin simply because green medicine is always supposed to be safe and of their easy availability. Another factor which emphasizes this attention is the incidences of harmful nature of synthetic drugs which are regarded as harmful to human beings and environment. The disadvantage is that herbal drugs are victims of adulteration. To meet the growing demands, the natural drug is easily adulterated with low grade materials. The misuse of herbal medicine or natural products starts with wrong identification [2]. Standardization and quality control are essential analytical tools to assure the correct identification of drugs. Advances in microscope technology and improvements in light and scanning electron microscopes have increased the accuracy and capabilities of microscopy as a mean of botanical identification. Adulteration and misidentification of herbal drug can cause serious health problems [3]. The increased usage of antibiotics has induced microorganisms to acquire resistance factors which have become a burning predicament [4].

Zingiber officinale Roscoe, (Ginger) belongs to family Zingiberaceae [5]. It is a perennial herb, with leafy stem up to $60 \mathrm{~cm}$. The rhizome is horizontal, branched, fleshy, aromatic, white or yellowish to brown. Leaves are narrowly or linear-lanceolate. Flowers are produced in a dense spike. It has been widely used all over the world. The Zingiberaceous plants have strong aromatic and medicinal properties and are characterized by their tuberous or non-tuberous rhizomes. $Z$. officinal rhizome (Ginger), has been a popular spice and herbal medicine for thousands of years, ginger has been used to help treat arthritis, cramps, rheumatism, sprains, sore throats, muscular aches, pains, constipation, vomiting, hypertension, indigestion, dementia, fever and infectious diseases, bacterial infections [6], as well as antioxidant effects that could have applications against certain types of cancer. The objectives of this study are to assess quality of $Z$. of ficinale herbal medicine for therapeutic value and authentication due to very little literature available.

\section{Material and Methods}

\subsection{Materials}

\subsubsection{Plant Materials}

Zingiber officinale rhizomes (fresh ginger) were purchased from a market in Khartoum (Sudan) in 2016, identified and authenticated at Medicinal and Aromatic Plant Research Institute National Central for Research Sudan.

\subsubsection{Bacterial Microorganisms}

The microorganisms selected for the study are:

Bacillus subtilis (NCTC 8236 (Gram +ve bacteria), Staphylococcus aureus (ATCC 25923(Gram +ve Bacteria), Escherichia coli (ATCC 25922 (Gram -ve bacteria), Pseudomonas aeruginosa (ATCC 27853 (Gram -ve bacteria). 


\subsection{Methods}

\subsubsection{Morphology}

The external structure of $Z$. officinale rhizome and its powder were determined and outlined.

\subsubsection{Anatomy}

\section{1) Powder study}

The powder of the rhizome was studied microscopically to outline the anatomical characters. The powder was tested for the presence of starch and oils using iodine and Sudan III stains respectively.

\section{2) Transverse section}

The fresh rhizomes were sectioned transversely using the methods described by [7] with some modifications.

\subsubsection{Anti Bacterial Tests}

\section{1) Preparation of the alcoholic extracts}

Extraction was carried out according to method descried by [8] Sukhdev et al. (2008). Fresh rhizomes were dried in shade and grinded using mortar and pestle. $50 \mathrm{~g}$ dried powder were extracted with methanol using soxhlet extractor apparatus. Extraction carried out for about eight hours till the solvent returned colorless at the last siphoning times. Solvent was evaporated under reduced pressure using rotary evaporator apparatus. Finally, extract allowed to air in Petri dishes till complete dryness and the yield percentage was calculated as followed:

Weight of extract obtained/weight of plant sample $\times 100$.

\section{2) Preparation of the aqueous extract}

$50 \mathrm{~g}$ of the plant sample was soaked in $500 \mathrm{ml}$ hot distilled water, and left till cool down with continuous stirring at room temperature. Extract was then filtered and freeze-dried till powdered extract obtained. Yield percentage was calculated as above.

\section{3) Preparation of bacterial suspensions}

One $\mathrm{ml}$ aliquots of a 24 hours broth culture of the test organisms were aseptically distributed onto nutrient agar slopes and incubated at $37^{\circ} \mathrm{C}$ for 24 hours. The bacterial growth was harvested and washed off with $100 \mathrm{ml}$ sterile normal saline, to produce a suspension containing about $10^{8}-10^{9}$ C.F.U/ ml. The suspension was stored in the refrigerator at $4^{\circ} \mathrm{C}$ till used.

The average number of viable organisms per $\mathrm{ml}$ of the stock suspension was determined by means of the surface viable counting technique [9]. Serial dilutions of the stock suspension were made in sterile normal saline solution and $0.02 \mathrm{ml}$ volumes of the appropriate dilution were transferred by micro pipette onto the surface of dried nutrient agar plates. The plates were allowed to stand for two hours at room temperature for the drops to dry and then incubated at $37^{\circ} \mathrm{C}$ for 24 hours. After incubation, the number of developed colonies in each drop was counted. The organisms tested were grown in broth over night to contain $10^{8}$ organisms per ml. Loop-full of diluted culture is spotted with a standard 
loop that delivers $0.001 \mathrm{ml}$ on the surface of each segment and then incubated at $37^{\circ} \mathrm{C}$ for 24 hours. The end point (MIC) is the least concentration of antimicrobial agent that completely inhibits the growth. Results are reported as the MIC in $\mathrm{mg} / \mathrm{ml}$.

\section{4) Testing for Antibacterial Activity}

The cup-plate agar diffusion method [10], was adopted with some minor modifications to assess the antibacterial activity of the prepared extracts. The agar was left to set and in each of these plates 4 cups (10 $\mathrm{mm}$ in diameter) were cut using a sterile cork borer (No. 4) and agar discs were removed. Plates were prepared in series of decreasing concentrations of the plant extracts in the following order 100, 50, 25, 12.5, 6.25; mg/ml. Alternate cups were filled with 0.1 $\mathrm{ml}$ sample using automatic microliter pipette and allowed to diffuse at room temperature for two hours. The plates were then incubated in the upright position at $37^{\circ} \mathrm{C}$ for 18 hours, after incubation the diameters of the resultant growth inhibition zones were measured, averaged and the mean values were tabulated.

\section{Results and Discussion}

\subsection{Morphological Characters of Z. officinale Rhizome}

The rhizome is buff colored, with aromaticodor. Taste is agreeable and pungent.

The rhizomes are laterally compressed, bearing short flat ovate and oblique branches on the upper side, with bud at the apex. The fracture is Short and fibrous. It gives positive test for starch and oils. The pharmacognostical characters of the powder of the rhizome of $Z$. officinale had been studied [11] and found that it contains starch, cellulose, protein, lignin, mucilage, tannin, calcium oxalate, fixed and volatile oils.

\subsection{Anatomical Characters}

Figure 1 shows transverse section of $Z$. officinale rhizome, it is formed of the following tissues:

Epidermis: The outermost layer and it is distinct continuous layer, consisting of a single row of rectangular cells.

Hypodermis: 3 - 5 layers of sclerenchyma cells.

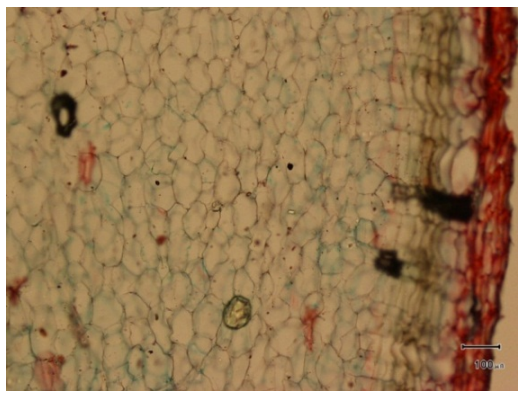

(a)

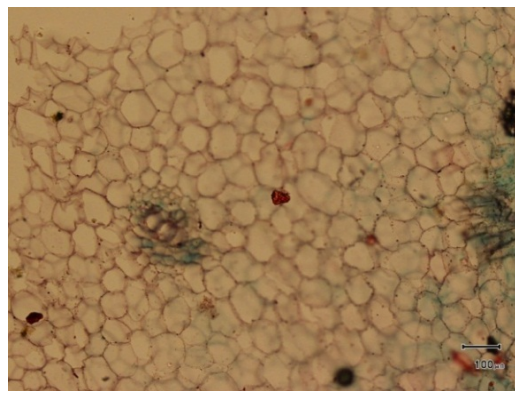

(b)

Figure 1. Transverse Section of $Z$. officinale rhizome. (a) Showing epidermis, hypodermis, cork and cortex; (b) Showing a vascular bundle. 
Cork region: composed of 6 - 7 layers of irregularly arranged, rectangular to tangentially elongated, slightly brown-colored cells, arranged in radial rows.

The cortex: composed of thin-walled large hexagonal to polygonal ground parenchymal cells filling the section. The cortical cells are heavily loaded with starch grains and oil droplets.

Vascular Bundles: Many scattered, collateral, closed. Each vascular bundle consists of phloem, composed of small thin-walled polygonal cells. These bundles have only one to three xylem vessels. No fibers are present enclosing these small bundles [3]. Most frequent microscopic structures observed into these subterranean stems includes cork and vascular tissues in varying amounts and abundant parenchyma, which often contains starch in large amounts. Chlorenchyma, palisade tissue, and aleurone grains are not present the powder of Zingiber officinale had studied macro and microbscopcally [12] and the dignostie characters of it are: pareixhyma cells unit at adherent oleo resin, parendyma cells with wrinklod) cell wall, ussel, ussel with parenchyma cells and staroh grains [13]. Talele et al. (2015) Stated that Ginger contains a many constituent like starch, fat, Gingerol and volatile oil [12]. Kumar et al. (2011) studied the transverse section of $Z$. officinale rhizome and described the same tissues found in this study.

\subsection{Percent Yield of Extracts}

The percentage yields of the methanolic and aqueous extracts were calculated, Table 1 demonistrates the percentages, they were found to be low. The percentage yield of the methanolic extract was higher than that of the aqueous extract.

\subsection{Antimicrobial Activity}

\subsubsection{Methanolic Extract}

Table 2 demonstrates the antibacterial activity of methanolic extract from therhizome of Zingiber officinale were evaluated. In vitro antibacterial activity was investigated by cork porous method. The most sensitive bacteria were bacteria:

Table 1. Percentage yields of the extracts.

\begin{tabular}{ccccc}
\hline \multirow{2}{*}{ Weight of sample } & \multicolumn{2}{c}{ Methanol } & \multicolumn{2}{c}{ Aqueous } \\
\cline { 2 - 5 } & Weight of extract & Yield \% & Weight of extract & Yield \% \\
\hline $50 \mathrm{~g}$ & $6.969 \mathrm{~g}$ & $13.938 \%$ & $1.942 \mathrm{~g}$ & $3.884 \%$ \\
\hline
\end{tabular}

Table 2. Antibacterial activity of the methanolic extract.

\begin{tabular}{cccccc}
\hline Concentration & 6.125 & 12.25 & 25 & 50 & 100 \\
\hline Staphylococcus aureus & 16 & 16 & 18 & 19 & 19 \\
Escherichia coli & - & - & - & - & 10.5 \\
Bacillus subtilis & 12 & 12 & 14 & 15 & 16 \\
Pseudomonas aeruginosa & 17 & 15 & 19 & 20 & 19 \\
\hline
\end{tabular}


Staphylococcus aureus (ATCC 25923). Pseudomonas aeruginosa (ATCC 27853) followed by Bacillus subtilis (NCTC 8236) but E. coli was found to be not sensitive except for $100 \mathrm{mg} / \mathrm{ml}$ concentration.

\subsubsection{Water Extract}

Table 3 demonstrates the antibacterial activity of water extract from the rhizome of Zingiber officinale were evaluated. In vitro antibacterial activity was investigated by cork porous method. The most sensitive bacteria were Pseudomonas aeruginosa (ATCC 27853), Staphylococcus aureus (ATCC 25923) was found to be sensitive for $50 \mathrm{mg} / \mathrm{ml}$ concentration but Bacillus subtilis (NCTC 8236) and $E$. coli were found to be not sensitive except for any of the concentrations tested. that ginger extracts have exhibited wide spectrum of antibacterial properties. Therefore, they can be used for preserving various foodstuffs against microbial spoilage and it can be incorporated into medications for topical antifungal or antibacterial therapy [14] as antibiotics and antifungal, therefore they can be used as a potential source of active ingredients for food. The results indicated that Zingiber officinale, extracts (water, ethanol, and chloroform), exhibited an antimicrobial activity against Escherichia coli and B. subtilis bacterial [15]. Z. officinale ethanolic extract has shown a wide range of influence on gram positive aerobic bacteria. This investigation of ginger has confirmed its significance, especially in the area of influence on tested staphylococci [16].

Figures 2-5 show Antibacterial activities of methanolic and water extracts against tested bacteria.
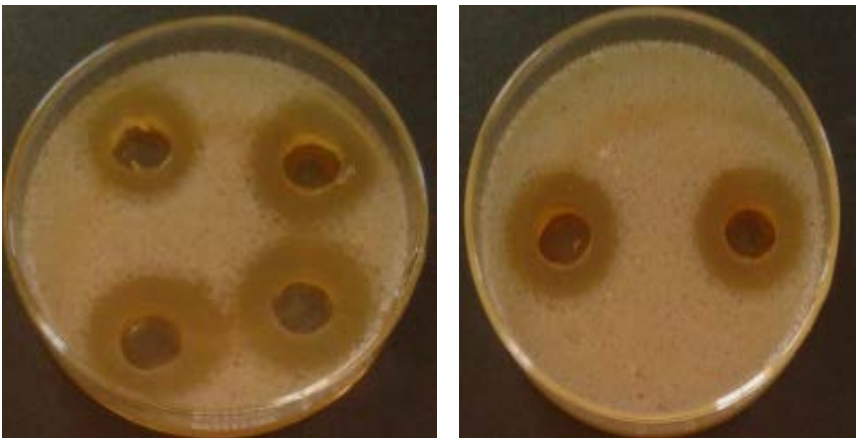

(a)
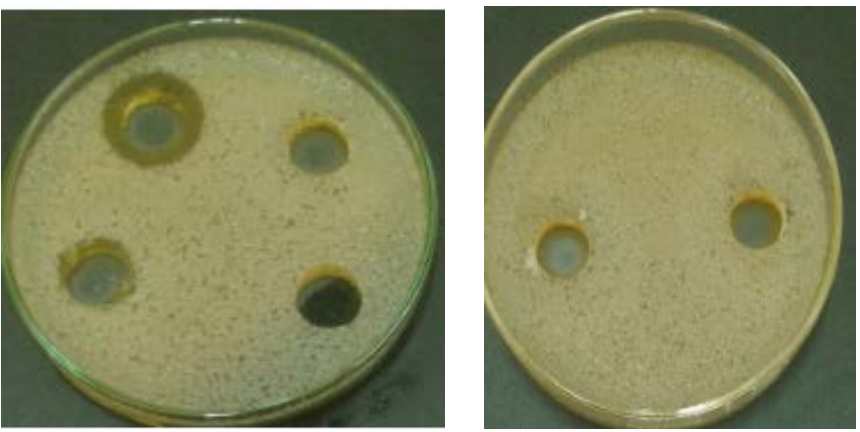

(b)

Figure 2. Staphylococcus aureus. (a) Alcohol extract; (b) Water extract. 


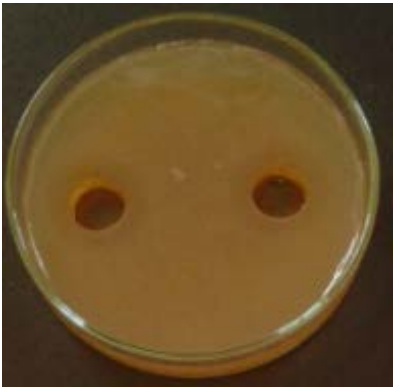

(a)

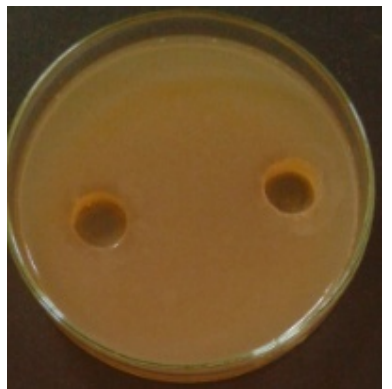

(b)

Figure 3. Escherichia coli. (a) Alcohol extract; (b) Water extract.

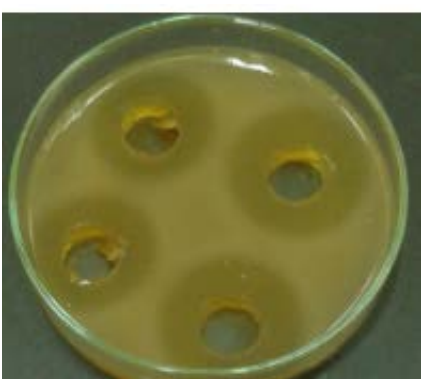

(a)

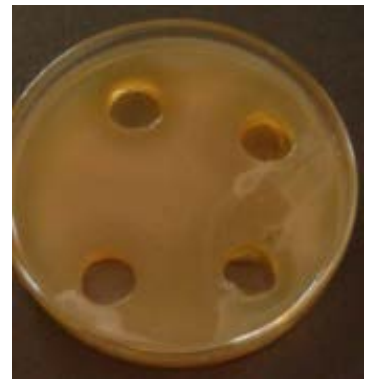

(b)

Figure 4. Pseudomonas aeruginosa. (a) Alcohol extract; (b) Water extract.
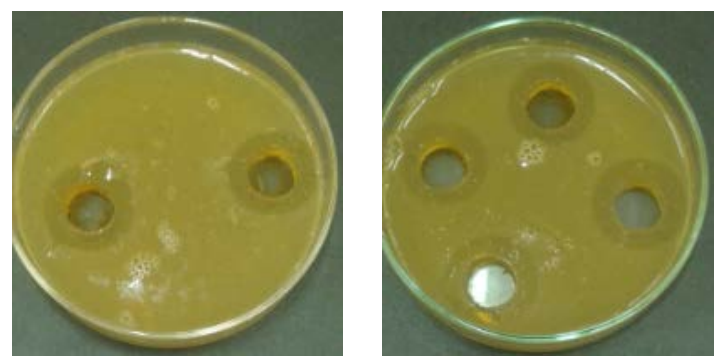

(a)

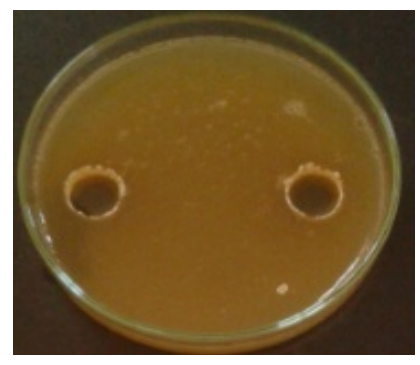

(b)

Figure 5. Bacillus subtilis. (a) Alcohol extract; (b) Water extract.

Table 3. Antibacterial activity of the water extract.

\begin{tabular}{cccccc}
\hline concentration & 6.125 & 12.25 & 25 & 50 & 100 \\
\hline Staphylococcus aureus & - & - & - & 13 & - \\
Escherichia coli & - & - & - & - & - \\
Bacillus subtilis & - & - & - & - & - \\
Pseudomonas aeruginosa & - & 10 & 12 & 12 & - \\
\hline
\end{tabular}

\section{Conclusion}

The morphanatomical result generated from this study would be useful in identification and standardization of $Z$. officinale rhizome materials towards quality assurance and also for preparation of a monograph on the plants. The study also revealed that this plant possesses some antibacterial properties. From the ob- 
tained results, we can indicate the methanol extract was superior to the water extract against the same tested microorganisms.

\section{Acknowledgements}

Acknowledgments are to Ustaz Hamza Tag Elsir for preparing the slides for the transverse sections.

\section{Conflicts of Interest}

The authors declare no conflicts of interest regarding the publication of this paper.

\section{References}

[1] WHO. The World Health Organization Report 2008-Primary Health Care.

[2] Dineshkumar, C. (2007) Pharmacognosy Can Help Minimizeaccidental Misuse of Herbal Medicine. Current Science, 3, 1356-1358.

[3] Serrano, R., da Silva, G. and Silva, O. (2010) Application of Light and Scanning Electron Microscopy in the Identification of Herbal Medicines Microscopy: Science, Technology, Applications and Education.

[4] Abimbola, K.A., Obi, C.L., Alabi, S.A., Olukoya, D.K. and Ndip, R.N. (1993) Current Status on Biotyping Antibiogram and Plasmid Profiles of E. coli Isolates. East African Medical Journal, 70, 207-210.

[5] Sharma, S., Vijayvergia, R. and Singh, T. (2010) Evaluation of Antimicrobial Efficacy of Some Medicinal Plants. Journal of Chemical and Pharmaceutical Research, 2 , 121-124.

[6] Tan, B.K.H. and Vanitha, J. (2004) Immunomodulatory and Antibacterial Effects of Some Traditional Chinese Medicinal Herbs: A Review. Current Medicinal Chemistry, 11, 1423-1430. https://doi.org/10.2174/0929867043365161

[7] Johansen, D.A. (1940) Plant Microtechnique. McGraw-Hill Book Co., New York.

[8] Swamim, S., Suman, H., Singh, P., Gennaro, K. and Dev, L. (2008) Extraction Technologies for Medicinal and Aromatic Plants. Rakesh International Centre for Science and High Technology Trieste.

[9] Miles, A.A. and Misra, S.S. (1938) The Estimation of the Bactericidal Power of the Blood. Journal of Hygiene, 38, 732. https://doi.org/10.1017/S002217240001158X

[10] Kavanagh, F. (1972) Analytical Microbiology. In: Kavanagh, F., Ed., Vol. 11, Academic Press, New York \& London, 11.

[11] Anubha, C., Sandeep, G. and Mohanlal, J. (2017) Pharmacognostical Evaluation of Rhizome of Zhngiberofficinale Rosc. European Journal of Pharmaceutical and Medical Research, 4, 324-328.

[12] Kumar, P., Jha, S. and Naved, T. (2011) Pharmacognostical Characterization of an Ayur Vedic Powdered Formulation: Panchsakar Churna. IJRPC, 1.

[13] Talele, P.B., Sharma, K.S., Dalvi, P.B. and Nandan, S.S. (2015) Isolation of Starch from Ginger rhizome (Zingiber officinale). Journal of Pharmacognosy and Phytochemistry, 3, 157-162.

[14] Hasan, H.A., Rasheed Raauf, A.M., Abd Razik, B.M. and Rasool Hassan, B.A. (2012) Chemical Composition and Antimicrobial Activity of the Crude Extracts Isolated from Zingiber officinale by Different Solvents. Pharmaceut Anal Acta, 3, 184. 
https://doi.org/10.4172/2153-2435.1000184

[15] Mostafa, A.A., Salem, Z.A. and Salem, R.H. (2016) Antimicrobialactivity of Some Plant Extracts and the Inhition Effect on Bacterial Cells Using Transmission Electron Microscopy.

[16] Grace, S., Saveetha and Sankari, S. (2017) Antimicrobial Activity of Ethanolic Extract of Zingiber Officinale-An in Vitro Study. Journal of Pharmaceutical Sciences and Research, 9, 1417-1419. 